\title{
Human Trafficking Incidence in Rwanda: Its Challenges, Prevention and Control
}

\author{
${ }^{1}$ Dr.Isaboke Peter Kennedy Nyataya, ${ }^{2}$ Gacinya John \\ ${ }^{1}(\mathrm{PhD}$-Sociology-Senior Lecturer), Director of Academic Affairs and Quality Assurance, University \\ of Tourism, Technology and Business Studies, Gisenyi Campus-Rwanda \\ ${ }^{2} \mathrm{MSc}$-Criminology-PhD Research Scholar -Mount Kenya University
}

\begin{abstract}
Rwandans like any other people in the rest of the world, suffer physically and psychologically during and after the transportation of victims of human trafficking to other parts of the world. It is observed that, occupational hazards in industries pose danger to the lives of victims of labour trafficking. It is also noted that sexually-abused victims of human trafficking risk catching HIV/AIDS pandemic. Ignorance, poverty, family conflicts and gender inequality have been found to be some of the key 'push' factors that drive individuals to seek economic opportunities elsewhere other than their home areas. Too, there exist some key 'Pull'factors that tend to influence individuals to leave their permanent residences with a view to searching better life opportunities in the perceived more prosperous countries than their home countries, hence, escaping from the incidences of family conflicts, poverty and unemployment. The main objective of the present study was to understand the challenges faced by the Government of Rwanda in its efforts to prevent and control the incidence of trafficking in the country. Qualitative research design and documentary technique were adopted for the study. The findings of the study showed that limited research, limited capacity for law enforcers in terms of trained personnel and equipment, limited awareness, insufficient legislation, presence of cultural norms and attitudes, globalization, social media and digital technology, porous borders, gender inequality, limited coordination and cooperation among different stakeholders and law enforcing agencies, were identified as the main challenges towards effective prevention and control of human trafficking in the country. Hence, the present researchers recommend that the Government of Rwanda should make efforts to educate and sensitise the public in general on the dangers of human trafficking. Besides, it should enhance its coordination and cooperation with other relevant institutions and agencies, improve the capacity of all law enforcers and ensure appropriates legislations are put in place and effectively implemented. In addition, the Government should put mechanisms in place directed towards the reduction of poverty and unemployment among its citizens, improve gender equality and educate the masses on cultural norms that may create enabling environment for the incidence of human trafficking in the country.
\end{abstract}

Keywords: Human trafficking, Incidence, Challenges, prevention and control.

\section{INTRODUCTION}

Human trafficking has been causing lots of suffering to mankind since $19^{\text {th }}$ century, (Derks, 2000 cited by Laczko \& Gozdziak, 2005). About twenty seven (27) million people are thought to be held as captives of human trafficking all over the world, (UNGIFT, 2008). Those held under captivity are represented in different forms of trafficking as in labour, sexual trafficking, illicit child adoption, Child military service, organ removal, child harvesting, domestic servitude and forced marriage, (UNODC,2009).

Between 800,000 and 4,000,000 people, mostly women and children are trafficked across international borders annually, (Ngwee \& Elechi, 2012). Europe receives about 400,000 illegal immigrants annually from Africa, Middle East and Asia, while 850,000 immigrants enter the United States of America. Middle East countries affected by civil war such as Syria, Yemen, Iraq and Afghanistan are source countries for refugees flocking to Europe fleeing war for better life in Europe (Africa centre for strategic studies, 2015).Over 1000 migrants and refugees are thought to have died while crossing the Mediterranean sea,(African centre for strategic studies,2017). Proceeds from human trafficking are quite enormous. Rahman (2011) estimated that $\$ 31.6$ billion is obtained from sexual exploitation and forced labour annually. About 12.3 million people worldwide are in slavery, serving bonded labour, child labour and sexual servitude, (ILO, 2005). 
Despite the fact that globalization and technology are seen as opportunities that allow international movement of people and goods easily, but, these have their own challenges. In the case of East African countries, people are free to move from one country to another through the East African community agreements. People are free to move from one country to another and hence, making it difficult for any one in identifying the trafficked and the trafficked not.

Free access to internet and social media easily inform people of the economic opportunities that exist and this, therefore serve as influencing factor for people to rush and tap these opportunities. In such arrangements the law enforcement is handicapped in identifying and controlling victims and perpetrators as noted by Asiimwe, (2014).

Cultural traditions in Africa for many centuries have undermined girls and women and hence, to a large extent marginalised them. This has led to girls and women starting to yearn for the their economic freedom and security, therefore, making it hard for law enforcement agencies identify and stop human trafficking amidst potential traffickers.

According to Aronowitz (2009), traffickers are keen to observe the vulnerabilities faced by children who are not supported by their families and offer attention, superficial love ,food ,clothes, housing and drugs in order to win their favour and traffic them. Thus, the victims make it easy for the traffickers to offend and difficult for the law enforcement officials to protect.

Asiimwe (Ibid), has observed that there is weak enforcement of laws and policies on human trafficking in Rwanda as there is lack of capacity in terms of trained personnel and equipment. More so, law enforcement officials lack the requisite knowledge on what constitutes human trafficking and mistake it to mean prostitution, smuggling, sexual abuse and labor abuse.

Lack of reliable data is mostly attributed to inadequate legislation that does not lay ground for operations against human trafficking to take place, (Laczko \& Gramegna, 2003).A lot of studies have been so much on victims of human trafficking than human traffickers themselves, their clients and law enforcement agencies involved in human trafficking, (Laczko and Gozdziak, 2005).Therefore, this poses a challenge in detection and investigation of both victims and traffickers respectively.

\section{Problem Statement}

Globally, Women and girls are mostly exploited in most of the unskilled labour. About $60 \%$ of the youth in poor countries are unemployed and Africa has the highest number of unemployed cases in the world. Nearly 20 million African men and women are migrant workers, (ILO, 2005).It was anticipated that by 2015 , one in ten Africans would migrate to work outside his or her original country, (ILO, 2005).

As a consequence, about 27 million people face human trafficking of different forms. $79 \%$ of the victims of human trafficking are women and girls who are sexually abused and from Africa. Over 800,000 people, mostly women and children are trafficked across international borders annually, (UNGIFT, 2008).About 55,000 people enter Europe from Africa every year, (Financial Action Task force, 2011). A big number of the migrants are from war torn countries such as Syria, Eritrea and Somalia while others are from West Africa. Human trafficking in this region of Africa has turned into a lucrative business of $\$ 10,000$ dollars per individual from Africa to Europe, according to the African Centre for Strategic Studies (2016).

The international law came with the initiation of the Palermo Protocol in 2000 as an international instrument to eradicate human trafficking. About 138 countries backed the agreement and 69 approved the anti-human trafficking legislation. This was followed by information flow and protection of victims of human trafficking and subsequent prosecution of offenders. But, later ON, these countries failed to maintain human trafficking counter -measures. It was a failure on part of the international organizations such as the United Nations that soon undermined the efforts of the Palermo Protocol, (UNGIFT, 2008). For instance, the United Nations Peace Keepers became part of the group that practised human trafficking. A splendid example is the Sri Lankan peace keepers that were expelled from United Nations peace keepers in Haiti in 2007, as Shelley noted.

Another limitation was that the international community failed to apply the law authoritatively. For example, there is reluctance on the part of some governments to apply the law which allows use of funds seized from human traffickers, (UNGIGT, 2008). It is further noted that a major weakness that 
involves most states is that there is no country that wills to cede even a small percentage of its sovereignty by so applying the international law as it is and as it was contracted among nations.

Tyldum \& Brunovskis (2005) observed that methods of data collection on human trafficking pose challenges because inferences drawn do not give a true picture of the reality. Some figures depicting the scope and trend can be misleading and this can undermine the programs and policies to be instituted. There is the issue of hidden population that makes it difficult to get the real picture of human trafficking in a given area as the size and boundary of the population cannot be estimated. Access to data can be difficult since issues like prostitution, labor market protection and immigration laws are highly politicized.

The US State Department does reward countries by way of providing foreign aid to countries that respond well to human trafficking counter measures and sanctions those countries by withdrawing of education, cultural and military support for those countries that are reluctant to institute counter measures to human trafficking, (US Department of State, 2016).Due to the fact that countries do not want to lose the aid, they misinform the extent of human trafficking and exaggerate the levels at which they respond to the problem of human trafficking, (Barnabe, 2012).

Since 2009, about 153 cases of human trafficking have been recorded by the Rwanda National Police (Tashobya, 2013). According to Kwibuka, (2016), about 74 cases of human trafficking were reported and recorded by the Rwanda National Police between 2015 and 2016.It could be that a good number incidents of human trafficking in the country go unreported due to the hidden nature of the crime. This adds weight to the already existing challenges in combating human trafficking in Rwanda. According to the IOM (2012), combating human trafficking has remained difficult in Rwanda because of the ignorance of the victims who are willing to be trafficked even when they not sure of the risks involved as long as they are promised jobs and education in the destination countries, ( Fletcher, 2014).

It is observed that sex trafficking is one of those incidents that women cannot dare report to police. The Government of Rwanda is as such obliged to keep silent over the matter because the population within its borders culturally does not want to be associated with sex matters, (Shelley, 2010).

Though the Government of Rwanda has had initiatives and programmes put in place to stamp out human trafficking in collaboration with international community, a good number of challenges stand on its way towards preventing and controlling human trafficking in the country.

\section{RESEARCH OBJECTIVE}

The main objective of the present study was to analyse the challenges faced by the Government of Rwanda its efforts to prevent and control the incidence of human trafficking in the country.

\section{LITERATURE REVIEW}

Globalization has become a world-wide challenge towards human trafficking, prevention and control. Human traffickers have become sophiscated, largely, due to easy of communication, transport and technology that flow globally. Traffickers are able to use these means to beat off the law enforcement officials, (Ghiggi, L et al., 2009).

According to Barner et al (2014), social inequality between the North and the South is the major contributor to human trafficking. Globalization has created a social economic gap between the North and the south. The North is favoured by better trade relations. The South produces law materials which are sold at low prices to the North which processes them and sells them at higher prices to the South. Ultimately, the North becomes developed as the South becomes poorer. This is why there is a divide between the developed North and the developing south. Social inequalities between the North and South are identifies in terms of income, assets, employment, access to knowledge, politics, medical services, social security and safety. The imbalance caused in the standards of living between the North and South is a 'pull' enough to affect the South in terms of human trafficking.

Barner et al, (Ibid), contends that social imbalance has caused migration of victims of human trafficking from West and East Africa to Europe respectively. Similarly victims of human trafficking have migrated from Balkans and former soviet countries to European Union. United states of America receive victims from Latin America and Europe as Asian countries send victims of human trafficking to developed parts of Asia such as Japan ,Taiwan and Hong Kong from Myanmar, Vietnam, Pakistan, 
North Korea, Thailand and Laos. This kind of immigration is difficult to contain for it is linked to opportunities that exist in Europe.

Bakery Seckan (2012), finds that there political and empirical challenges in studies of sex trafficking. Countries do not report sex trafficking within their borders for fear of losing international reputation. There are also financial considerations, for example between 1993 and 1995 South East Asian countries such as Indonesia, Thailand, Malaysia and Philippines, earned between 2 and $14 \%$ their GDP from sex tourism. Further, it is noted that the UN peace keepers in Haiti were the ones behind prostitution and sex trafficking in 2007.The said led to expulsion of 100 peace keepers from Sri Lanka.

According to Hughes (2014), digital communication technology and devices have challenged the combat of human trafficking in the EU community and elsewhere. The internet has promoted prostitution and sex related crimes. Human traffickers using internet are ahead of the legislation and law enforcement. Legislation should be geared towards making laws that apply to use of digital material, storage and transmission of the information they hold. Internet has been used to facilitate quick transmission of information for sex venues and sex tours, advertising the availability of children for sexual exploitation, provide sites to purchase pornography, exchange or purchase child sexual abuse images. Traffickers place false advertisements on employment sites in order to lure victims into the trap.

Bales (2007), finds that there is difficulty in disclosing information from victims because of gender considerations. Trafficked women fail to aid the investigations because of the stigma and shame they expect to suffer once they narrate all they went through during the process of trafficking. Men fear to lose their dignity and masculinity if they tell stories of what they went through that is not manly and out of culture. More to that, victims of human trafficking distrust police agents for fear of being regarded as criminals, victims can also refuse cooperation because they do not take themselves as victims.

The issue of minimum age upon which the youth can acquire employment is not uniform internationally. In some of Latin American countries hit by poverty and economic stagnation minors risk human trafficking because most states in the region register 14 years as the minimum age at which people are regarded as mature and acquire employment,( Ghiggi et al.,2009).

It is observed that international law has limitations of its use across the borders of countries and once used can be very expensive. This is so because human trafficking is a crime that carries many crimes in it and in this case takes a lot of time, energy and resources and countries with limited resources remain reluctant to pursue cases of human trafficking across borders.

Hernandez (2006), opines that challenges of combating human trafficking are present in the United States of America because the public is not aware of what constitutes human trafficking. There are also attitudes and bias of the law enforcement officials who fail to identify and help victims of human trafficking controlled by human traffickers. Law enforcement agencies think that victims of human trafficking can be illegal immigrants or prostitutes.

There is scarcity of reliable and complete data on the scope of sex trafficking for minors in United States of America. Besides, law enforcement agencies have not been trained to identify minors who are trafficked and continue to call them teenage prostitutes. The biggest challenge is that victims of human trafficking never consider themselves as victims of human trafficking. A good number of victims for human trafficking are female and from social backgrounds that render them vulnerable, (Parsons and Cray, 2014).

Laczko and Gramegna (2003) observe that failure to obtain reliable data for most countries is attributed to absence and inadequate legislation or as such legislation which is not used to tackle the problem of human trafficking. These authors also assert that victims are also hesitant to testify in the court of law and these results in few convictions. Many organizations are making attempts to combat human trafficking, but there is no single agency that acts as a focal point to coordinate and harmonize the data from various sources. There is also reluctance to share data for reasons that such data for some countries is classified, others have a policy of restricted data. Some agencies could be having poor data while source countries are not shared data for origin countries are implicated in human trafficking. 
There is a major concern on the part of researchers who fail to obtain reliable data on human trafficking and therefore the scope of human trafficking as researchers fail to obtain the target population for victims. The population that obtains is a hidden population and has no size and boundaries. Victims are concealed and cannot be obtained by tools of research. One cannot get a sampling frame. The stigma attached with human trafficking makes the sampled population un cooperative (Ruby, A. et al., 2012).

Data on the number and type of victims, essential to combat human trafficking needs to be improved in EU member countries. The 2013 report on victims and traffickers provided indicated in $27 \mathrm{EU}$ members and 7 other complying members was not complete and therefore full analysis of human trafficking would not be satisfactory, ( Hughes,2014).

In EU $62 \%$ and $31 \%$ rank for sexual trafficking and labour trafficking respectfully and $7 \%$ for other forms of human trafficking, but awareness campaigns in EU carried out indicated that Labour trafficking was not in any way known to exist,(Hughes,2014).

Prostitution is an offence in most countries and punishments for it differ and in some instances prostitution is tolerated by law enforcement officials. There are both voluntary and involuntary prostitution and it is very difficult to discern the two and distinguish who is trafficked and who is not. It is also possible for the victim to change the story and testimony provided to the prosecution because of time lag between the reporting the crime of human trafficking, arresting the trafficker and court processes. During this period the victim and relatives fear reprisals on the part of offenders and the victim can be advised to disappear. The examination and cross examination of the court process is much feared by the victims of prostitution for they do not want to relive the period of suffering, (Wanchai, 2013).

There are gaps in terms of cooperation between countries. Victims rescued in one country and traffickers arrested in the destination country may not be informed in the origin country. The traffickers are thus not prosecuted and when the victim returns home the country of origin is not informed of the story of trafficking, (Wanchai, 2013).

Potgieter (2013) argues that there is a missing link in finding a solution to the problem of human trafficking. There is lack of consensus on the definition as provided by the UN Palermo protocol. The Palermo protocol is criticized for not giving the real direction of fighting human trafficking. The Palermo protocol more or less addresses human trafficking as a law enforcement issue and not human security issue, and thus addresses symptoms and does not give solutions. Solutions should be sought from the root causes of human trafficking and these are the socio-economic problems prevailing in the society.

Potgieter (Ibid), further, asserts that human trafficking should be looked at as human security concern; human security ensures that citizens are secured. It emphasizes prevention and is people oriented and seeks to address the root causes of problems. Human security emphasizes solving human induced problems such as migration, disparities in economic inequality, the rise in killer diseases, population growth, environmental degradation and security fears of individuals and communities. Human security looks at the root causes of political instability, economic problems and social injustices.

Ionescu(2007), point out that states still apply state centric methods to fight against human trafficking. They still apply realist views on security which see state as an object of security. State centric view security of the state by guarding the country against external threats. How about the internal socioeconomic factors that breed human trafficking? Three Ps have been used as a tool kit to combat human trafficking, and these are; Prosecution, Prevention and Protection. But how much of this tool kit has been used. There has been use of prosecution with the associated legislation and criminalization of human trafficking among states. On analysis, protection has been left to civil society in most countries and prevention of human trafficking has been ignored. Thus; victims of human trafficking have not been empowered to get out of the socio-economic problems.

In Nigeria, human trafficking centres on poverty, unemployment and entrenched corruption. There is a belief that money can buy everything. Families of successful but originally trafficked children in Benin community in Nigeria wield a lot of influence because of money realized from their children who do prostitution. There is also forced marriage condoned by state and religion authorities where girls, women, divorcees and sex workers have to marry as required by the traditions, (Lawrence, 2014). 
In South Africa, Carol (2010), notes that research programme to combat human trafficking of 2008 was not welcome in some quarters. Foreign embassies denied receiving interviews indicating that human trafficking does not exist in their sectors. Fears were there with government officials who were not willing to give information on human trafficking and those who did so preferred to remain anonymous. Hence, efforts to develop programmes, policies, strategies are hampered by challenges of meeting reliable data as a baseline. South Africa lack referral mechanisms to support victims of human trafficking. Further, observes that it is these mechanisms that would assist South African institutions to identify victims of human trafficking, other challenges are poor investigations because of lack of trained personnel, lack of cooperation between prosecution and victims. As an example, prostitutes who do not want to testify in the court. Besides, neighbouring countries such as Zimbabwe, Swaziland, Namibia, Malawi, Lesotho, DR Congo, Botswana and Angola have no comprehensive law prohibiting human trafficking, she points out.

One major challenge in combating human trafficking is the extended family relationships that exist among communities in Africa. African culture and customs accept privileged members in their community to demand services which are not paid for those members of the family who are socioeconomically bad. Men can clear and prepare land as women do the weeding and planting at little or no cost, (Njoh, 2012).

According to Naud'e (2009), migration in Sub Saharan Africa has risen as a result of conflict, economic opportunities and environmental degradation. Low economic growth can cause conflict that forces people to migrate. Water scarcity and land degradation can also result in a conflict and migration. In both cases migration results in internal displaced people, refugees, asylum seekers and finally trafficked people as people become vulnerable. Conflicts, droughts, economic stagnation and refugees are persistent in Sub Saharan Africa and means to overcome human trafficking in the face of afore mentioned vulnerabilities are slim.

Onuoha (2013), opines that Africa lacks the political will to combat human trafficking, has inadequate legislation and lacks coordination to protect victims of human trafficking, poor law enforcement and high level corruption. Angela (2011), adds that, lack of political will can be well identified with the Tanzania government where most of the sensitization activities against human trafficking are done by IOM and non- governmental organizations, yet the government of Tanzania has enacted laws against human trafficking. Communities in Tanzania do not distinguish between human trafficking and child fostering, where child fostering is seen as an extended family affair, but masking exploitation features.

Eastern Africa region has been characterised by poor governance, conflicts, poverty, corruption and socio-economic inequalities, and this is why the region faces problems of human and arms trafficking. Respective governments face challenges of awareness and capacity to deal the issue of human trafficking, (UNODC, 2009).

\section{MeThodology AND MATERIAL}

In the present study, the researchers made use of documents available in various institutions as the main sources of data for the study. They included published books, periodicals, scientific papers, press, journals, magazine, electronic sources, to name a few..

\section{RESUlTS AND DiscuSSION}

It was noted that challenges of fighting human trafficking in Rwanda include and are not limited to; Ignorance, limited cooperation, limited data and porous borders, (RNP, 2015).

\subsection{Ignorance}

Dodo Obediah et al.(2012), argues that human trafficking exists in Rwanda and has been facilitated by ignorance, poverty and conflicts. People avail themselves for exploitation when they have no jobs. During the conflict people flee their homes and become refugees and these are conditions that breed human trafficking.

According to Florence Shu-Acquaye (2013), there is limited awareness in as far as the problem of human trafficking that pertains to Rwanda. More to that the anti-human legislation in place has not been applied to its full potential. Also the capacity of law enforcement personnel and other government officials like the migration department need to be enhanced in order to deal with the crime of human trafficking effectively, (Florence and Shu-Acquaye, 2013). 
Binagwaho (2013), observes that demand for prostitution encourages human trafficking. In Rwanda prostitution is present and the major cause has been poverty, social exclusion by the immediate family, the criminal justice system and local administration.

Preventing and controlling human trafficking is still a challenge in Rwanda for law enforcement agencies charged with the responsibility of fighting human trafficking react to it once informed of it. The police are unable to detect and prevent human trafficking before it occurs. Victims can only know they are in danger after they have reached the destinations as they are initially promised jobs and education. Response to human trafficking occurs once the victim sounds an alarm and in danger, (Rwanda National police News, 2015).

Karuhanga (2015), notes that there is a flawed mind-set about what foreign countries possess. There is always thinking among the parents and their children that life abroad is better life than what it is in Rwanda. This kind of belief has always pulled to migrate abroad and in the end trafficked.

\subsection{Limited Cooperation and Coordination}

According to the US State Department ( 2013), Rwanda, should have a coordination centre to link together all departments concerned with the vice of human trafficking, however, Rwanda does not have an inter -ministerial body to coordinate all sectors that deal with human trafficking and this hampers coordination and cooperation in terms of anti-trafficking policy and operations.

\subsection{Limited and Unreliable Data}

According to US State Department (2010), Rwanda happens to be the only country in the SubSaharan Africa that has considerably undertaken demobilization and reintegration of former child soldiers, enhanced public awareness programs, opened up rehabilitation centres for victims of human trafficking and other gender related matters, but there is less knowledge on the scope and gravity of human trafficking in Rwanda, US State department, (2013), notes.

\subsection{Porous Borders}

Assistant Commissioner of Police, Tony Kulamba, of Rwanda National Police pointed out that porous borders is among the key challenges faced in trying to prevent and control human trafficking in Rwanda, (Rwanda National Police News,2015).Most of the borderline is not secured as it should be. Border security is mostly maintained at ports of entry. Human traffickers take advantage of weak state capacities to control and manage the border line. There is also poor intelligence sharing between states that share the border where as cross-border communities that are difficult to administer and often uncooperative in managing borders, as Wafula, (2011), observed.

\subsection{Lack of Adequate Capacity}

Rwanda National Police highlights that the issue of human trafficking is prevalent in Rwanda and capacity building in terms of personnel is a requirement to combat the vice, (New times, 2015). Furthermore, the Rwanda National police lacks enough personnel, skills and equipment, (Chelsea Plante et al., 1993).

Resources in terms of the equipment and personnel need to be enough to handle operations that go along with human trafficking. To this effect, these have not been enough in Rwanda. There has been lack of training in terms of victim identification, (US Department of State, 2013). More police need training and equipments are required. A splendid example is that there have been insufficient labour inspectors to cover the country yet the ministry of public service and labour provides few resources to complete employees' operations, (US State Department, 2013).

\subsection{Cultural Attitudes and Norms}

Abbot Pamela et al. (2015), indicates that cultural attitudes still hinder women development. Women are still denied their rights that enhance their development. They still regard land to belong to their husbands even if officially (documentary) co-owned. Women are few, in off-farm activities. Representation of women has not yet permeated to low levels of the Rwandan society. However, Representation of women is still in higher positions like the parliament and other senior positions such as permanent secretaries, she further, pointed out.

In Rwanda, land is small and does not provide useful alternative occupation and so people move to urban centres to work as prostitutes, (Gasana et al. , 2015).Gender equality is still hampered by social 
norms, gender roles and stigma, low levels of education, skills and confidence that results in unequal levels in decision making,(USAID/RWANDA, 2015).

\subsection{Conflicts}

Human trafficking among young boys and girls has been taking place in conflict areas of Sub Saharan. Rwanda's past conflicts and the current conflict in Burundi are splendid examples where young men were/are recruited to join the war expecting rewards at the end, as noted by Rahman (2011).

\subsection{Family Breakdowns}

Unstable families are on the increase in Rwanda for the mere reason that many people who form up the families were exposed to violent past, specifically violent genocide period, the situation is as such and children in the families run away from home and are thus vulnerable to human trafficking, (Asiimwe, 2014).Gasana (2015) adds that children who migrate from the rural to Kigali city for better life are a social challenge. Street children increase every day and has no quick fixes.

\subsection{The Hidden Nature of Human Trafficking}

According to Gender Monitoring Office in Rwanda (2015), the crime of human trafficking is committed clandestinely and in most cases the victim does not complain and so reports about the crime do not reach criminal justice system . This is why evidence of the crime is hard to find and few convictions are handled in Rwanda as reported by the Minister of Justice Johnson Busingye when he said that, "Between 2011 and 2014, 24 cases were registered by the prosecution, among which 10 were filed. Nine cases were tried; four among them were convicted while other five were acquitted".

\subsection{Unemployment and Poverty}

According to Asiimwe (2014), women and children aged between 16 and 40 years are the ones trafficked out of Rwanda. They are at most times semi-literate and poor suffering from socioeconomic hardships and as they strive to get out of the poor socio-economic conditions by migrating where there are economic opportunities. They are mostly taken to Uganda and Kenya for sexual and domestic exploitation. She also states that, it is the insufficient enforcement of laws and policies, low status of women, poverty, Rwanda's political past and insufficient preventive mechanisms that are responsible for human trafficking occurrence in Rwanda

\subsection{Weak Legislations}

Article 251 of the Penal Code of Rwandan laws, states that, 'any person who participates in any way, personally or through an intermediary, in trafficking a person out of Rwanda to a foreign country by: means of deception, use of force, threat or any other form of coercion; or by taking advantage of his or her troubles with the authorities, shall be liable to a term of imprisonment of one to three years and a fine of Rwf 500, 000 to Rwf 2 million. The penalties under this Article will be doubled if the victim is a child'. In any case the punishment meted for human trafficking is so little to affect general deterrence as a crime, (Bishumba, 2017).

Other than weak legislations, there is also a challenge of less experienced prosecutors in following up cases of human trafficking as pointed out by the Rwanda Prosecutor General -Mutangana that, "As investigators begun to get a grip of the human trafficking crime, we saw an increment because in 2012/2013, we recorded 10 files but not all of them reached a conclusion. There was a shift from 2014/2015, when we recorded 51 files and concluded 41 meaning that 10 had no evidence to support them. For 2015/2016, we recorded 32 cases, and completed 31', (Bishumba, 2017)

\section{CONClusion}

In the present study, it is clearly noted that the challenges towards the prevention and control of human trafficking come from within and from without the country. They are of socio-economic nature, which include poverty, ignorance, social exclusion of prostitutes, gender inequality which hamper human trafficking combat as they render individuals vulnerable to human trafficking. Besides, legislation is not so comprehensive to support the criminal justice system in fulfilling its law enforcement obligations.

Furthermore, no single country can fight against human trafficking single-handedly, since human trafficking takes an international character. For any success in the Fight against the vice, there is need 
to seek international cooperation and coordination. Hence, Rwanda as country needs to enhance her full cooperation with all the relevant agencies and people from within its borders as well from those from outside the country.

Researches on human trafficking in Rwanda are still at their infant stage as the scope of human trafficking is still uncertain and this makes it difficult to plan for its prevention and control.

The capacity of law enforcement agencies in terms of training is still wanting and this also applies to the logistics. Lastly, The Rwandan borders stretch for many kilometres and it is very difficult to man such a porous borders.

There is, too, in Rwanda, inadequate statistical data that indicate the magnitude of human trafficking in the country. Little research has been done in the field to establish the gravity of human trafficking. Knowing the gravity of human trafficking can enable the Government to plan ahead in terms of personnel and material resources to deal with the crime of human trafficking.

There is limited coordination and cooperation in the fight against human trafficking in Rwanda. There should be a coordinating office for all stake holders, so that data on human trafficking and logistics can be put together for use in various operations necessary for fighting human trafficking.

\section{RECOMMENDATIONS}

Human trafficking should be fought with a preventive outlook. The root causes of the problem of human trafficking should be identified as these are the ones that render individuals vulnerable. All the efforts should be directed towards the amelioration of the contemporary social problems such as poverty, unemployment, rural-urban migration, low levels of education, killer-diseases that leave children orphaned. The socio-economic inequalities, including low levels of income should be given special attention by all for these serve as with a view to wanting to succeed in the prevention and control of human trafficking in the country in particular and in the region in general.

Human trafficking should be fought from a human security approach and this goes with analyzing the socio-economic problems at stake and seeking ways and means to eradicate them. Human security aspect will solve human induced problems such as migration, political instability economic problems, disparities in economic inequality, social injustices, the rise in killer diseases, population growth, environmental degradation and security fears of individuals and communities. The social inequality existing between the North and South that pulls individuals to seek for employment and education in the North should be ironed out by 'reciprocal direct investment' targeting developing states.

Rwanda government needs to improve the capacity of law enforcement officials, enhancing cooperation and coordination among countries as well as enacting comprehensive laws that support the criminal justice system to operate to the full capacity.

\section{REFERENCES}

[1] Abbot, P. (2015). The promise and Reality: Women right's in Rwanda. Working paper N0.5, (School of social sciences: University of Aberdeen and Dixon Makunda), pp.28-40.

[2] African Centre for Strategic Studies. (2015).Migrants to Europe through Mediterranean sea. Department of Defense.

[3] Angela, M. (2011).Child trafficking in Tanzania: Exploring the experiences of trafficked girls in Dar- es-Salaam, Tanzania, P.90.

[4] Aronowitz, A. Alexis. (2009). The global trade in human beings. USA: Praeger publishers. P. 56.

[5] Asiimwe, F. (2014). Factors pre- disposing women and girls to human trafficking in Rwanda: A baseline survey and needs assessment report, Kigali,Pp.19-36

[6] Bales, K.et al. (2007). Overview of challenges in investigating human trafficking challenges: Lessons learned and best practices, FBI Law Enforcement Bulletin, 76(4), Pp.188-189.

[7] Bakary,S.(2012). Sex trafficking: Trends, challenges and limitations of international law.

[8] Barner, J.R., et al. (2014), Socio-Economic Inequality, Human Trafficking, and the Global Slave Trade,p.149-152

[9] Binagwaho, A.(2013).Developing human rights based strategies to improve health among female sex workers in Rwanda, Health and human rights journal,12(2). 
[10] Bishumba,N.(2017,Feb 20).GBV: Prosecutor calls for tougher punishment. The new times,P.1,

[11] Carol, A. (2010). Tsireledzani: Understanding the dimensions of human trafficking in South Africa, p.25.

[12] Chelsea Plante et al, (1993).Rwanda security reform,P.4.

[13] Derks, A.2000 "Combating trafficking in South-East Asia: a review of policy and

[14] Programme responses", Migration Research Series, no.2, IOM, Geneva. European Commission

[15] Dodo,O.et al,.(2012).Human trafficking in Zimbabwe: An Impediment to development, International Journal of Humanities and Social Science, 2(7).

[16] Gasana, A. (2015). Street Trading, Street-Connected Children and Young People, Delinquency and On-Street Prostitution in the City of Kigali: Problems and Practical Solutions.

[17] Gender monitoring office in Rwanda. (2014). Rwandans called for more collective efforts

[18] Ghiggi, L.et al. (2009). Human trafficking and transnational and organized crime.PP, 1-11

[19] Harelimana, J.B.(2015).Research methodology for economic social sciences and Management. INES RUHENGERI: Musanze.

[20] Hernandez, M. (2006). Challenges to Combating Human Trafficking: The U.S. NGO Response, Department of sociology Ohio State university.Pp.2-17.

[21] Hossain $\mathrm{M}$ et al. (2010). The relationship of trauma to mental disorders among trafficked and sexually exploited girls and women. American Journal of Public Health, , 100(12):2442-49.

[22] Hughes, D.M. (2014). Trafficking in Human Beings in the European Union: Gender, Sexual

[23] Exploitation and Digital Communication Technologies, Sage journals.Pp.2-6.

[24] Human rights watch. (2003). Children without Parents: Victims of Abuse and Exploitation: Rwanda Lasting Wounds: Consequences of Genocide and War for Rwanda's Children, 15( 5).

[25] ILO (2005), A Global Alliance against Forced Labour, Report of the Director-General, 93rd Session, Report I (B).

[26] IOM. (2010). Diverse Human Trafficking Trends in East African Region Highlights Urgent Need for Greater Protection.

[27] Ionescu, M. (2007). A Human Security Approach to Anti-trafficking Policies in the EU:

[28] Tackling the Structural Sources of Vulnerability, Pp.218-219.

[29] Karuhanga,J.(2015,Oct 1).We all have a role to play to end human trafficking, officials say. The newtimes, p.1.

[30] King, L. (2017) International law and human .International law journal. Boston University

[31] Kwibuka, E. (2016, July 1).Rwanda: MPs hold dialogue on human trafficking. The New times, p.1 retrieved,April 2017

[32] Laczko, F. \& Gozdziak, E. (2005).Data and research on human trafficking: A global survey, Geneva: International office of migration, 43(1/2), p.14

[33] Lawrence, B.N. (2014).Nigeria's human trafficking situation in 2014: A Research Sythesis, Center for strategic intelligence research, p.3-8.

[34] Marshall,P.(2011).Rethinking trafficking prevention: A guide to applying behaviour

[35] Muteti, S.M. (2014).Human trafficking in Kenya, Pp.70-80. Naud'e,W. Drivers of Force: Causes and faces of forced migration, Migration and displacement in Sub Saharan Africa,39,Pp.19-23.

[36] (2011).Human trafficking in the era of Globalization: The case of Trafficking in the Global Market Economy, Transcience Journal, 2(1), p.68.

[37] Ngwe,J.E. \& Elechi,O.O. (2012) .Human trafficking: The modern day slavery of 21st century.African Journal of criminology and justice studies. 1.6(1\&2).

[38] Njoh,A.J.(2012). Combating Forced Labour and Human Trafficking in Africa: The Role of Endogenous and Exogenous Forces, African review of economic and finance 4(1), South Africa: Print services, p.38.

[39] Onuaha, B.(2013). Human Trafficking in Africa: The Role of Universities in Teaching and Research, Journal of social science, 34(1), P.61-64. 
[40] Parsons, C. and Cray, A. (2014). 3 Key Challenges in Combating the Sex Trafficking of Minors in the United States, Center for American Progress.

[41] Rwanda National Police News,(2015), The ordeal of human trafficking victim; RNP response,

[42] Ruby, A. et al. (2012).Anti-trafficking legislation in Sub-Saharan Africa: Analyzing the role of coercion and parental responsibility, Fourth interdisciplinary conference on human trafficking, 2012,p.4.

[43] Shu-Acquaye, F. (2013). Human Trafficking: Trends in Africa, journal of international law, Gonzaga University

[44] The New times, Rwanda, (2015), Police strengthen fight against human trafficking, Retrieved from

[45] Tashobya, A. (2014, Oct, 9). Where are the victims of human trafficking Taken? The New times, p.1,

[46] Tyldum.G \& Brunovskis. A, (2005). Describing the Unobserved: Methodological Challenges in Empirical Studies on Human Trafficking. Data and Research on Human Trafficking: A Global Survey. Geneva, pp, 17-34.

[47] UNODC. (2009).Promoting the Rule of Law and Human Security in Eastern Africa,Pp.9-11

[48] US state department,. (2010).Human trafficking in Rwanda,

[49] US state department, (2013).Trafficking in persons report: Country Narratives,

[50] UN.GIFT. (2008): An introduction to human trafficking, vulnerability, impact and action (USA: New York), p.71

[51] US State Department.(2010).Trafficking in persons report.

[52] USAID/RWANDA. (2015). Gender analysis: Valuing open and inclusive civic engagement project.

[53] Wafula,O.(2011). Border Management and Security in Africa. The borders Institute: Kenya.Pp.7-12

[54] Wanchai, R. (2013).Human trafficking: A challenge to Thailand and world community, Resource material, N0.87, p.136. 